St. Louis has experienced minor earthquake damage at least 12 times in the past 200 years. Because of this history and its proximity to known active earthquake zones, the St. Louis Area Earthquake Hazards Mapping Project will produce digital maps that show variability of earthquake hazards in the St. Louis area. The maps will be available free via the internet. They can be customized by the user to show specific areas of interest, such as neighborhoods or transportation routes. (Photograph looking west from a geophysical measurement site in east St. Louis, Mo., by Dave Hoffman.)

Earthquakes currently cannot be predicted, but scientists can estimate how strongly the ground is likely to shake as the result of an earthquake. Earthquake hazard maps provide one way of conveying such estimates. The U.S. Geological Survey (USGS), which produces earthquake hazard maps for the Nation, is working with local partners to develop detailed maps for urban areas vulnerable to strong ground shaking. These partners include the Missouri University of Science and Technology, Missouri Department of Natural Resources, Illinois State Geological Survey, Saint Louis University, Missouri State Emergency Management Agency, and URS Corporation.

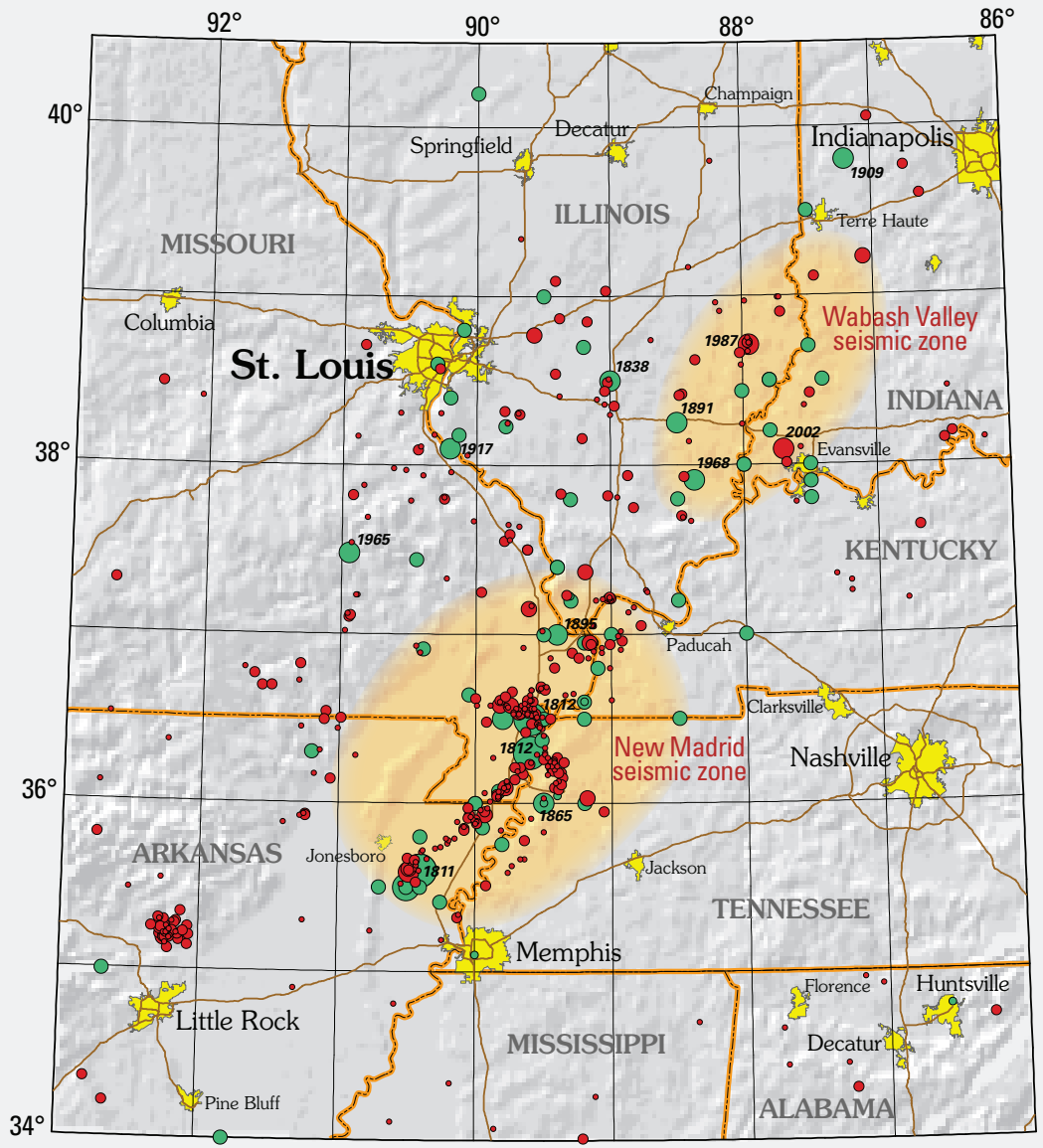

Earthquakes (circles) of the New Madrid and Wabash Valley seismic zones (orange patches). Red circles are earthquakes that occurred from 1974 to 2002. Green circles are earthquakes that occurred prior to 1974. Larger earthquakes are represented by larger circles. Yellow patches show larger urban areas.

\section{What is earthquake hazard?}

Earthquake hazard refers to a measure of the shaking, or ground motion, during earthquakes that can damage our built environment. The hazard depends on the magnitudes and locations of likely earthquakes, how often they occur, and the properties of the rocks and sediments that earthquake waves travel through. In the central United States, earthquakes occur along the New Madrid and Wabash seismic zones and in a zone of earthquakes that is scattered across southern Illinois and eastern Missouri.

\section{Who uses earthquake hazard maps?}

Public and private groups can use hazard maps for planning, mitigation, and response efforts to minimize losses resulting from earthquake shaking. Portfolio managers in the lending, insurance, and wealth management industries can use the maps to better manage risk exposure. Planning and zoning professionals can use the maps for hazard considerations in locating new development, critical facilities, and transportation corridors. Business continuity managers can use the maps to minimize earthquakerelated losses to their facilities, supply networks, and market share. The scale of the maps will not allow them to be used in a site-specific manner, but rather as a guide as to where more detailed studies are needed.
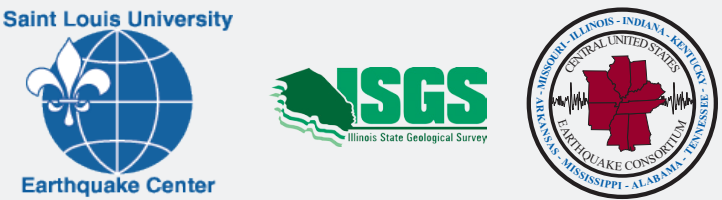

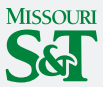

MEMPHIS

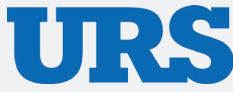




\section{Making Earthquake Hazard Maps}

Geologists map earth materials at the ground surface. Properties of these surficial materials, how deeply they extend, and properties of the bedrock below them are determined from measurements made in boreholes and cores drilled for construction projects and from oil, gas, mining, and water-well data. Information about the subsurface is obtained from imaging techniques, much like X-ray or ultrasound imaging is used to view the interior of the human body. These data are then combined to construct a three-dimensional (3-D) model of the layering of rock, soil, and alluvium.

Soil (weathered bedrock), loess, and alluvium layers change the way earthquake waves travel through them from an earthquake below. The 3-D model describes the layering beneath any location, and is used to calculate how the shaking from the waves will vary from place to place. For example, the sediments in the river floodplain may amplify some types of shaking more than at sites located on the upland areas.

The investigations done to produce the St. Louis area hazards maps will result in a variety of other products. Among these are maps of the surficial geologic materials as well as maps showing the likelihood of liquefaction. Liquefaction occurs when water-saturated sediments lose their cohesive strength during violent ground shaking. An online database of sediment properties determined in this project is also planned.

For more information contact:
Robert A. Williams
U.S. Geological Survey
Denver Federal Center
P.O. Box 25046, MS 966
Denver, CO 80225-0046
rawilliams@usgs.gov
St. Louis Hazard Mapping website:
http://earthquake.usgs.gov/regional/
ceus/urban_map/st_louis/index.php
Earthquake Hazards Program:
http://earthquake.usgs.gov/

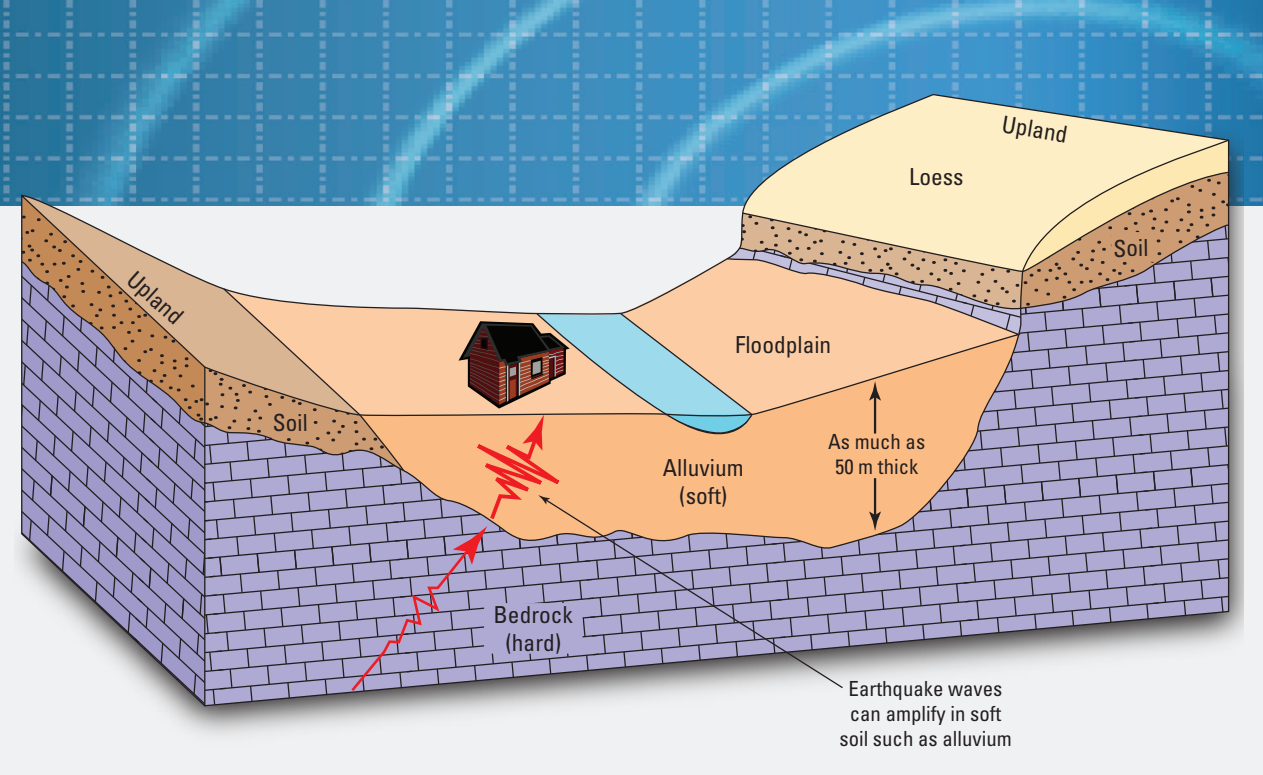

The diagram above is a block model showing simplified geology typical of the St. Louis area. Loess is a soft sediment carried and deposited by wind during the last glacial episode about 15,000 years ago; soils are soft materials often developed by weathering of bedrock; alluvium is soft river-deposited sediment that comprises most of the Missouri and Mississippi River floodplains. Structures located in the floodplains will likely experience stronger ground shaking and a greater likelihood of liquefaction. Bedrock is most commonly a hard 350 million-year-old limestone in the St. Louis area. Structures built on or near bedrock, such as in the upland areas out of the floodplains, will tend to have lower levels of earthquake ground shaking. Earthquake hazard maps, like the ones in development for St. Louis, provide needed information for the design of new structures and retrofitting of existing ones.

The inset box shows a preliminary seismic hazard map for the St. Louis, Mo., area, recently completed by Chris Cramer at CERI University of Memphis and Deniz Karadeniz and Dave Rogers at Missouri University of Science and Technology. The differences in seismic hazard between the national-scale and St. Louis area maps result directly from including the effects of near-surface soft sediments in the urbanscale map. Earthquake hazard maps such as these will help the region prepare for future earthquakes by showing, in detail, the potential variability of earthquake ground motion.
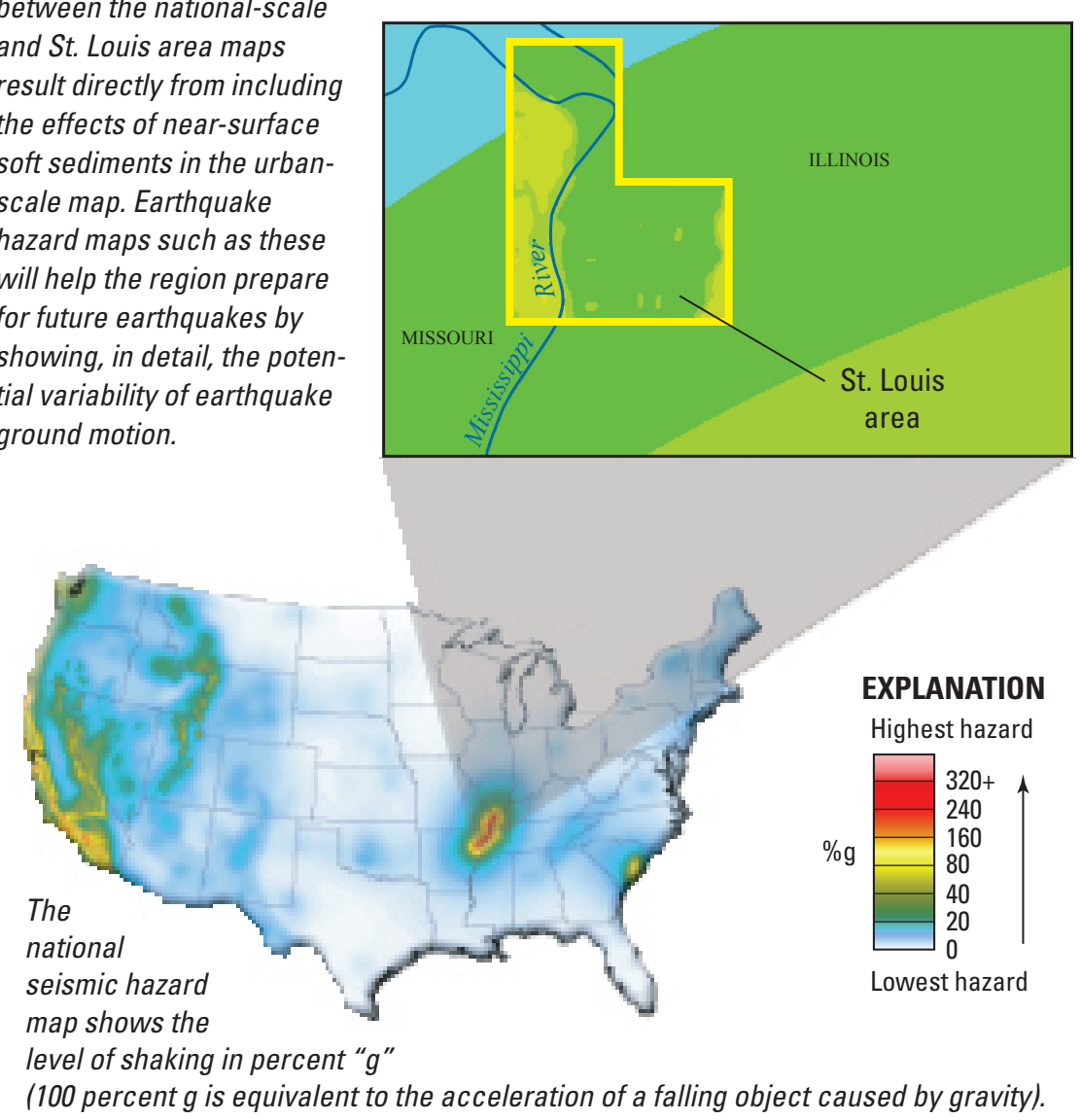